\title{
Comparison of Risperidon \& Olanzapine for Extrapyramidal Side Effects on Schizophrenic Patients in Haryana, India
}

\author{
Pankaj Jain ${ }^{1 *}$, Rajeev K Singla ${ }^{2 *}$, Rohit Gundamaraju ${ }^{3}$, Baishakhi Dey ${ }^{4}$, Varadaraj Bhat $\mathrm{G}^{5}$ \\ ${ }^{1}$ Vertex Legal Solutions, Rohtak-124001, Haryana, India \\ ${ }^{2}$ Division of Biotechnology,Netaji Subhas Institute of Technology, Sector-3, Dwarka, New Delhi-110078, India \\ ${ }^{3}$ Department of Physiology, Faculty of Medicine, University of Malaya, Malaysia \\ ${ }^{4}$ School of Medical Science \& Technology, Indian Institute of Technology, Kharagpur-721302, India \\ ${ }^{5}$ Manipal College of Pharmaceutical Sciences, Manipal University, Manipal, Karnataka-576104, India
}

Address for Correspondance: Pankaj Jain, jainp7@gmail.com ; Rajeev K Singla, rajeevsingla26@gmail.com

\begin{abstract}
The present study was conducted with an aim to investigate the extrapyramidal side effects (EPS) produced by two antipsychotic drugs viz. risperidone and olanzapine. It was found that both risperidone and olanzapine have significant EPS and EPS produced by risperidone and olanzapine do not differ significantly during the course of therapy. There is a significant difference at four weeks and six weeks between risperidone group and olanzapine group. Demographic data did not have any prediction on EPS. ( 2014 iGlobal Research and Publishing Foundation. All rights reserved.
\end{abstract}

KEYWORDS: Risperidon; Olanzapine; Schizophrenia; Extrapyramidal Side Effects.

ABBREVIATIONS: EPS- Extrapyramidal Side Effects; SAS - Simpson Anagus Scale; ICD International Classification of Disease.

\section{INTRODUCTION}

Schizophrenia is a major public health problem that affects approximately one percent of the population worldwide resulting in excessive mortality with a $20 \%$ shorter life expectancy and a ten percent suicide rate [1]. Schizophrenia is diverse in nature and covers a broad range of cognitive, emotional and behavioral domains and includes abnormalities in emotional expression, social interaction, perception, inferential thinking, language, attention, volition and drive [2].

Antipsychotics medications were introduced in early 1950's. These include two major classes: dopamine receptor antagonists and serotonin dopamine antagonists. Despite all developments all antipsychotics show some of the adverse drug reactions, which include sedation, hypotension, extrapyramidal symptoms and anticholonergic effects, hormonal effects, photosensitivity, tardive dyskinesia and weight gain for some newer antipsychotic drugs [3].

Sometimes the adverse drug reactions are so prominent that they hamper the patient's life. Extrapyramidal symptoms are the most common to all of the Antipsychotics though less frequent in newer Antipsychotics. Extrapyramidal symptoms include:

- Akathesia: motor restlessness

- Dystonia: result of sustained muscle contraction and 


\section{Indo Global Journal of Pharmaceutical Sciences, 2014; 4(2): 91-99}

- Parkinson like side effects: tremor, rigidity and poverty of facial expression. Drooling and excessive salivation is also common. A shuffling gait may be seen.

In case of antipsychotics the extrapyramidal side effects are very important as these can hamper the patient's life [4]. Moreover these extrapyramidal side effects lead to decrease in patient compliance [3]. It is found that Indians are more prone to extrapyramidal side effects [5]. That's why it is pertinent to study extrapyramidal side effects of antipsychotics. The present study is done to evaluate extrapyramidal symptoms of two newer antipsychotics risperidone and olanzapine which happen to be most commonly prescribed newer antipsychotics and also considered as first line treatment in schizophrenia. As no such study was available for patients from Haryana state.

\section{ANTIPSYCHOTIC AGENTS}

In early 1950 s some antipsychotic effects were obtained with the extracts of Rauwolfia plant and then large doses of purified active alkaloids risperine. Due to large number of adverse effects now it is not used clinically [6]. Antipsychotic medications introduced in 1950s, have revolutionized the treatment of schizophrenia after the discovery of antipsychotic properties of chlorpromazine by Delay and Denikar [7]. About 2 to 4 times as many patients relapse when treated with placebo, as do those treated with antipsychotic drugs $[8,9]$.

Adverse effects of antipsychotic drugs: Both typical and atypical antipsychotic drugs are not free from adverse effects. The main adverse effects are: anticholinergic side effects (dry mouth, blurring of vision, constipation), sedation, rash, photosensitivity, thermoreagulation dysfunction, lower seizure threshold, lethargy, mental confusion, orthostatic hypotension, ECG changes, hyperprolactinemia, elevated liver transaminases, blood dyscrasis, weight gain, sexual dysfunction, amenorrhoea, infertility, gynaecomastia, galactorrhoea and extrapyramidal symptoms which include parkinsonism like symptoms, acute muscle dystonias, akathisia, malignant neuroleptic syndrome and tardive dyskinesia [10-12].

\section{EXTRAPYRAMIDAL SYMPTOMS [13-17]:}

Extrapyramidal Symptoms are believed to arise due to dopaminergic blockade in the striatal areas of the brain that influence motor control. Although the reported incidence of extrapyramidal symptoms is probably related to assiduousness with which they sought, there is no doubt that they present a major impediment to patient compliance and clinical recovery. The major extrapyramidal symptoms are:

Parkinsonism: Typical manifestations are rigidity, tremor, hypokinesia, mask like faces, shuffling gait.

Acute muscular dystonias: Bizarre muscle spasms, mostly involving linguo-facial muscles- grimacing, torticollis, and locked jaw. The occurrence of acute dystonias is consistent with block of the dopaminergic nigrostriatal pathway, and there is evidence that the relative selectivity of atypical antipsychotic drugs for the mesolimbic/ mesocortical pathway accounts for the diminished risk of acute dystonias [18].

Akathisia: Restlessness, feeling of discomfort, apparent agitation [19].

Malignant neuroleptic syndrome [20]: It occurs at high doses of potent agents; patients develop marked rigidity, immobility, tremor, fever, semiconsiousness, fluctuating blood pressure and heart rate.

Tardive duskinesia: Occurs late in therapy. Manifests as involuntary facial and limb movements like constant chewing, pouting, puffing of cheeks, lip licking. Tardine dyskinesia is associated with a gradual increase in the number of $\mathrm{D}_{2}$ - receptor sites in the striatum, which is less marked with the atypical antipsychotic drugs [2122].

According to present guidelines for treatment of schizophrenia the atypical antipsychotics are first line of drugs to treat positive as well as negative symptoms as they are better tolerated and equal or better efficacy [10, 23-24]. Among atypical antipsychotics risperidone and olanzapine are more commonly prescribed.

\section{EXTRA PYRAMIDAL SIDE EFFECTS ARE UNACCEPTABLE [25]}

EPS are a common and serious drawback to the use of antipsychotic drugs. In addition to the discomfort and distress caused to patients, EPS may contribute to poor compliance and ultimately poor treatment outcome. The results of clinical trials with the new generation of atypical antipsychotics suggest that they are associated with a reduction in EPS. All of the new-generation agents produce substantially fewer EPS. But still atypical antipsychotics need to be evaluated for their EPS. ${ }^{27}$ The present study is done to study EPS of risperidone and olanzapine prescribed on patients from north India. 


\section{MATERIALS\& METHODS}

\section{STUDY SAMPLE}

The study sample consisted of 70 patients attending psychiatry OPD at Pt. B.D. Sharma PGIMS, Rohtak, India and who fulfilled the ICD-10 criteria for schizophrenia. The patients in the age range of 18 years to 70 years were considered for study. The diagnosis was confirmed by the consultant psychiatrist as per ICD-10 criteria.

The patients and the key relatives were interviewed in detail, together and individually. Relevant information regarding the past one year was gathered from different sources viz. family members, relatives and doctor's report if available.

The information was collected on a specially prepared case report form (CRF) which compromised the following:

(a) Pro forma showing demographic profile

(b) Consent form

(c) Simpson Angus Scale for measurement of EPS

The patients were screened for enrolment in study as per the following inclusion and exclusion criteria.

\section{INCLUSION CRITERIA}

1. The patient has been presented in OPD of Psychiatry department for the first time.

2. Age between 18 years to 70 years

3. Either sex

4. Patient is prescribed with monotherapy.

5. Dose prescribed should be less then $6 \mathrm{mg}$ per day in case of risperidone and less then $15 \mathrm{mg}$ per day in case of olanzapine.

\section{EXCLUSION CRITERIA}

1. Any co morbid illness.

2. EPS present on basal day.

3. Pregnancy and lactation.

4. Patient with continuous history of alcohol and/or drug abuse.

5. Patients with high risk of suicide.

6. Patient taking any anti parkinsonism medication.

7. Smoking

\section{TOOLS}

\section{SIMPSON ANAGUS SCALE (SAS) [26]}

It is a ten-item instrument developed by G.M. Simpson and J.W. Anagus and utilized to measure the symptoms of the parkinsonism or parkinsonian side effects related to the use of antipsychotic medications. It is the most commonly used rating scale for Parkinsonism in clinical trials over the past 30 years. The scale has items that measure the parkinsonian symptoms of rigidity, tremor, akinesia and salivation. The ten items are rated on a fivepoint scale $(0=$ complete absence of the condition, $4=$ presence of condition on extreme form). A majority seven of the ten items, measure rigidity in different parts of the body with only one item (gait) looking at the symptoms of akinesia, a common side effect associated with the use of antipsychotic medication. The items are easily scored after a simple neurological examination and observation of the patient's gait. The global score is the sum of all the scores divided by the total number of items i.e. divided by ten. Final scores of up to 0.3 are considered within the normal range, score equal to and more than 0.3 shows significant EPS. The SAS is very widely used in clinical trials for evaluating the side effects of antipsychotic medications. The time taken to complete the scale is ten to fifteen minutes.

\section{ADMINISTRATION OF SCALE}

All the patients and reliable attendants were made to feel comfortable and were interviewed by the investigator and various parameters viz. Gait, Arm, Shoulder Shaking, Elbow rigidity, Wrist Rigidity, Leg Pendulousness, Head Dropping, Glabella Tap, Tremor and Salivationwere measured.

After measuring all the items each item is given the score ranging from zero to four. Added up the score of each item and divided by 10 . The figure thus obtained is used to evaluate the presence or absence and significance of EPS. If the total score is less than 0.3 than it is considered as non significant EPS.

\section{GROUPS}

For the purpose of analysis the total of sixty patients were divided into two groups each compromising of thirty patients. Group I includes thirty patients who were prescribed Risperidone and group II includes thirty patients who were prescribed Olanzapine.

\section{FOLLOW -UP}

Patients were followed up every week for first two weeks and then fortnightly up to six weeks. Patients were advised to come for follow up if needed in between. The scale was applied at basal week, two week, four week and at six week. 
Indo Global Journal of Pharmaceutical Sciences, 2014; 4(2): 91-99

\section{RESULTS\& DISCUSSION}

The sample in the present study comprised of 70 patients of schizophrenia diagnosed as per ICD-10 and fulfilling the inclusion criteria as lay out. The mean age of patients was $38.09 \pm 14.41$ years (Table 1).

Table 1 Age wise distribution

\begin{tabular}{|c|c|c|c|c|c|}
\hline \multirow{2}{*}{$\begin{array}{c}\text { Age } \\
\text { Years) }\end{array}$} & \multicolumn{3}{|c|}{ Group } & \multirow{2}{*}{ Total } & Percentage \\
\cline { 2 - 4 } & Group I & Group II & Group III & 7 & 10 \\
\hline$<20$ & 2 & 4 & 1 & 2 & 28.57 \\
\hline $21-30$ & 11 & 7 & 2 & 19 & 27.14 \\
\hline $31-40$ & 7 & 9 & 3 & 24 & 34.29 \\
\hline$>40$ & 10 & 10 & 4 & $38.09 \pm 14.41$ & \\
\hline Mean age & $36.30 \pm 13.18$ & $38.77 \pm 15.32$ & $44.40 \pm 15.88$ & \\
\hline
\end{tabular}

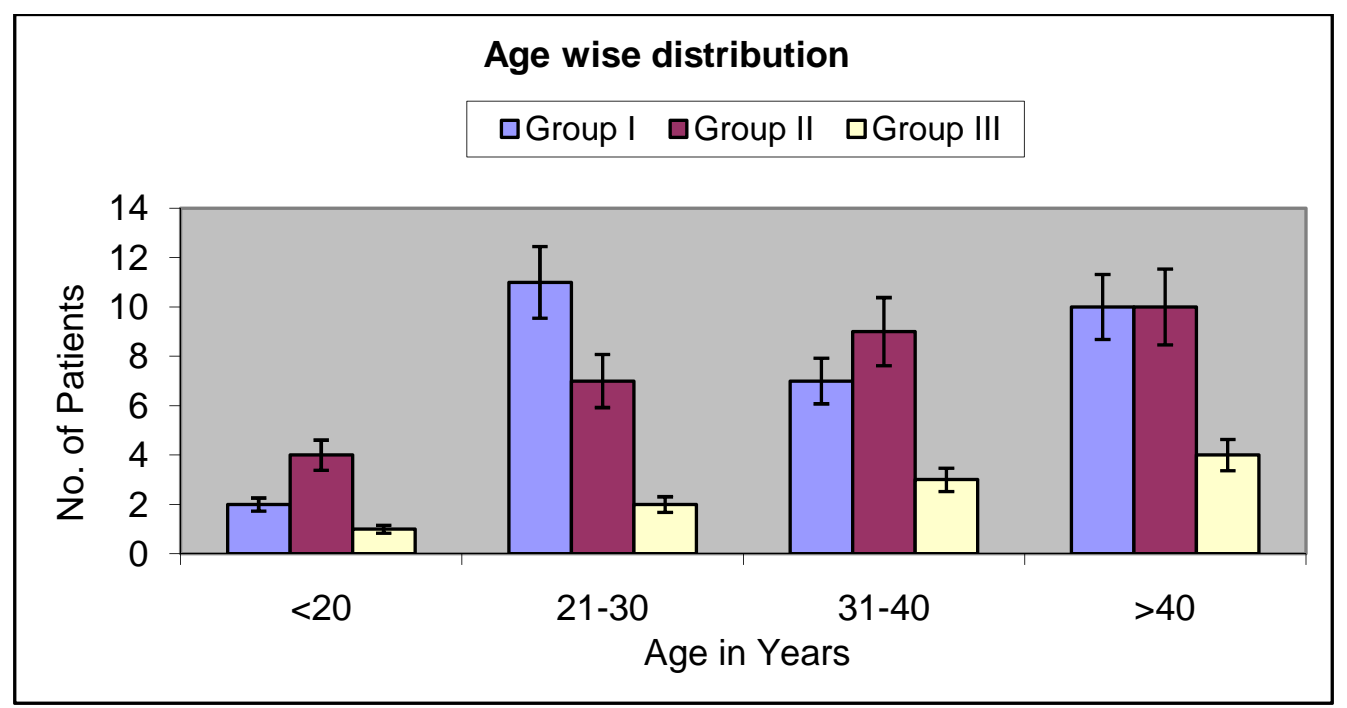

Table 2 Sex wise distribution and marital status

\begin{tabular}{|c|c|c|c|c|c|}
\hline \multirow{2}{*}{ Category } & \multicolumn{3}{|c|}{ Group } & \multirow{2}{*}{ Total } & \multirow{2}{*}{ Percentage } \\
\cline { 2 - 4 } & Group I & Group II & Group III & & 64.29 \\
\hline Male & 22 & 18 & 5 & 45 & 35.71 \\
\hline Female & 8 & 12 & 5 & 25 & 15.71 \\
\hline Single & 6 & 5 & 0 & 56 & 80.00 \\
\hline Married & 23 & 23 & 10 & 3 & 4.29 \\
\hline Widow & 1 & 2 & 0 & \\
\hline
\end{tabular}


Indo Global Journal of Pharmaceutical Sciences, 2014; 4(2): $91-99$

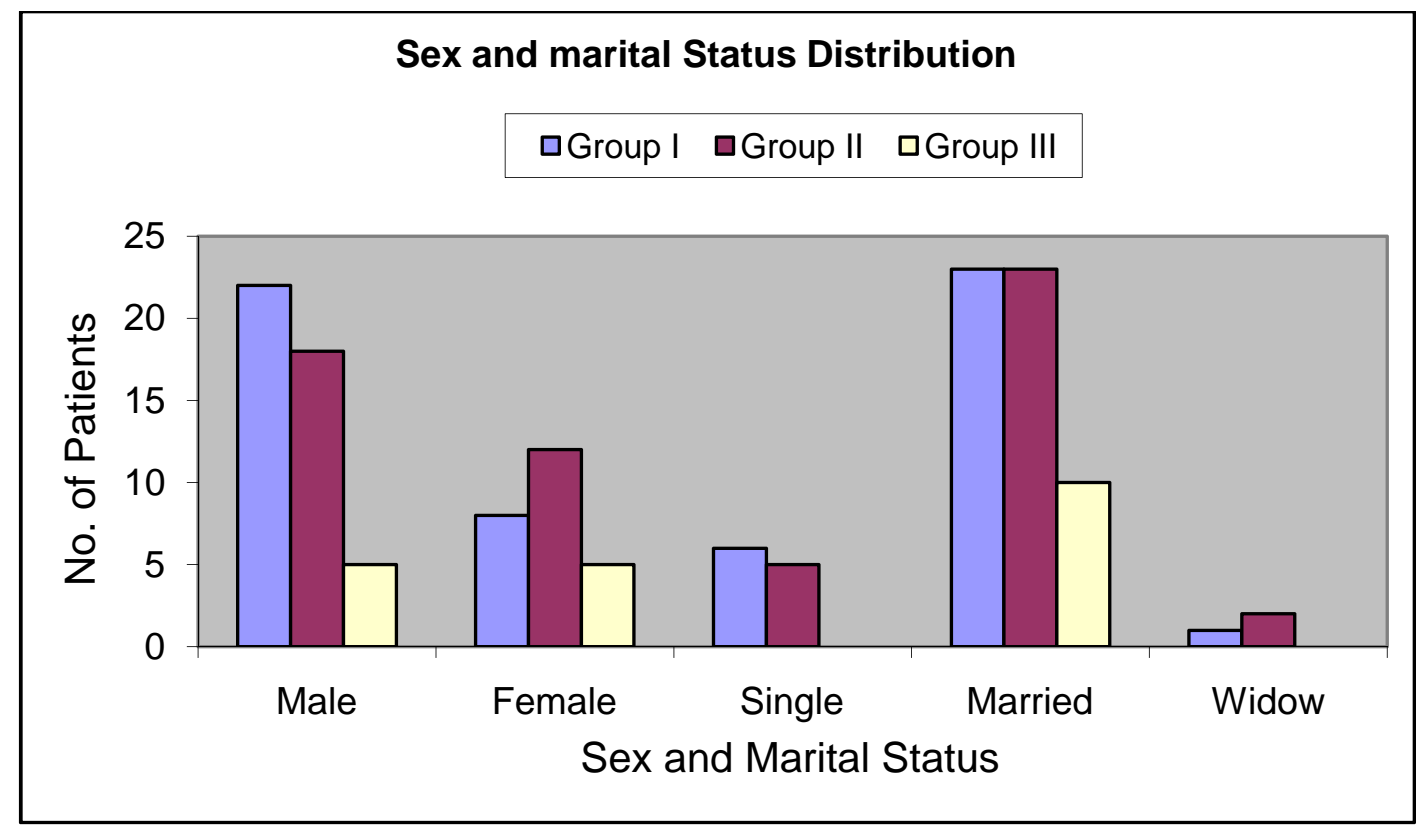

Table 3 Patient's education status

\begin{tabular}{|l|l|l|l|l|l|}
\hline \multirow{2}{*}{ Category } & Group & \multicolumn{2}{|c|}{ Total } & \multirow{2}{*}{ Percentage } \\
\cline { 2 - 5 } & Group I & Group II & Group III & \multicolumn{2}{|c|}{} \\
\hline Illiterate & 15 & 15 & 7 & 37 & 52.86 \\
\hline Primary \& Middle & 9 & 5 & 2 & 16 & 22.86 \\
\hline Matric & 6 & 8 & 0 & 14 & 20.00 \\
\hline Graduate \& above & 0 & 2 & 1 & 3 & 4.29 \\
\hline
\end{tabular}

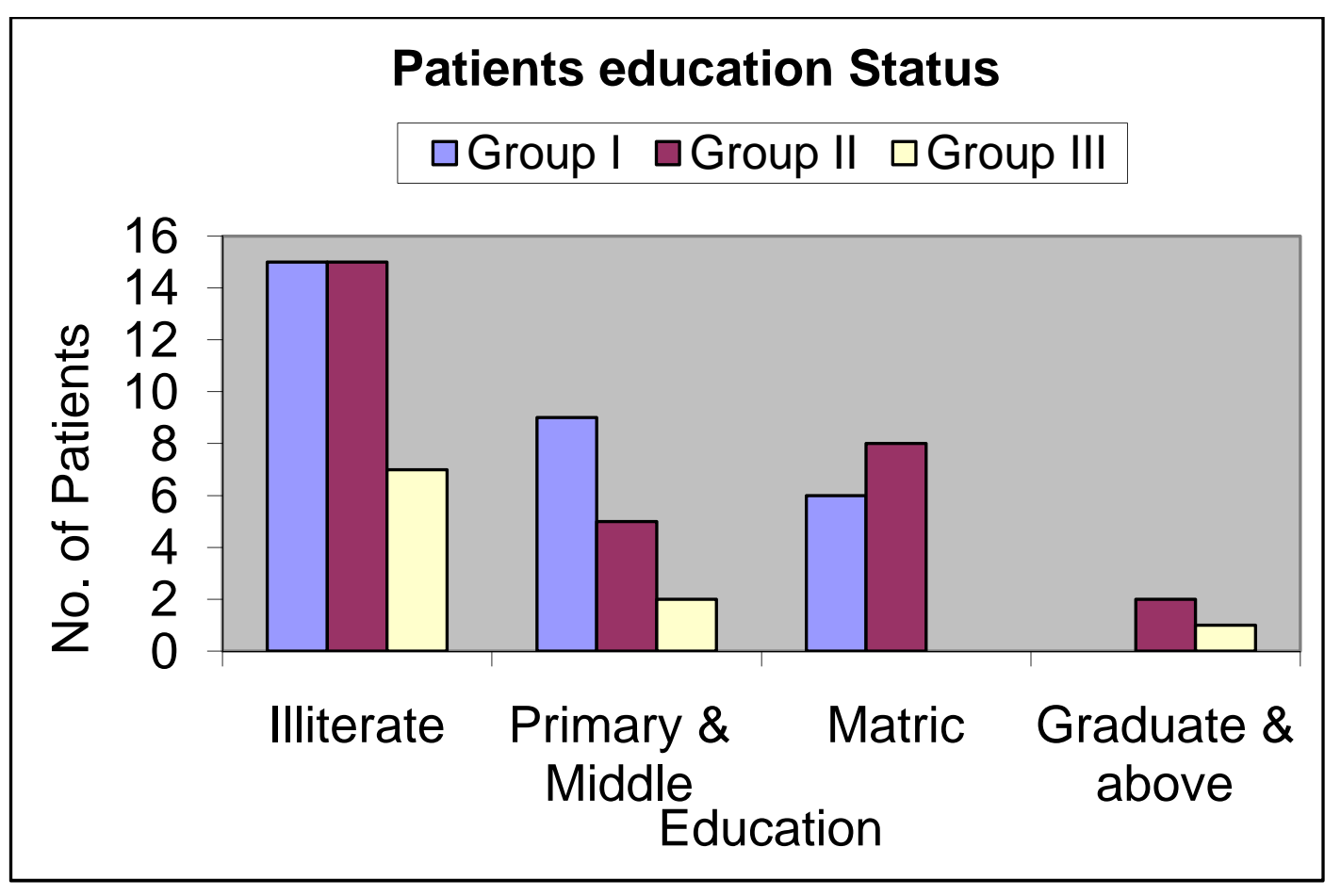


Indo Global Journal of Pharmaceutical Sciences, 2014; 4(2): $91-99$

Table 4 Patient's occupation status

\begin{tabular}{|c|c|c|c|c|c|}
\hline \multirow{2}{*}{ Category } & \multicolumn{3}{|c|}{ Group } & \multirow{2}{*}{ Total } & \multirow{2}{*}{ Percentage } \\
\cline { 2 - 4 } & Group I & Group II & Group III & & 17.14 \\
\hline Unemployed & 5 & 6 & 1 & 24 & 34.29 \\
\hline Farmer & 13 & 9 & 2 & 3 & 4.29 \\
\hline Laborer & 2 & 0 & 1 & 25 & 35.71 \\
\hline Housewife & 8 & 12 & 5 & 1 & 1.43 \\
\hline Retired & 0 & 1 & 0 & 5 & 7.14 \\
\hline Others & 2 & 2 & 1 & & \\
\hline
\end{tabular}

\section{Patients Occupation status}

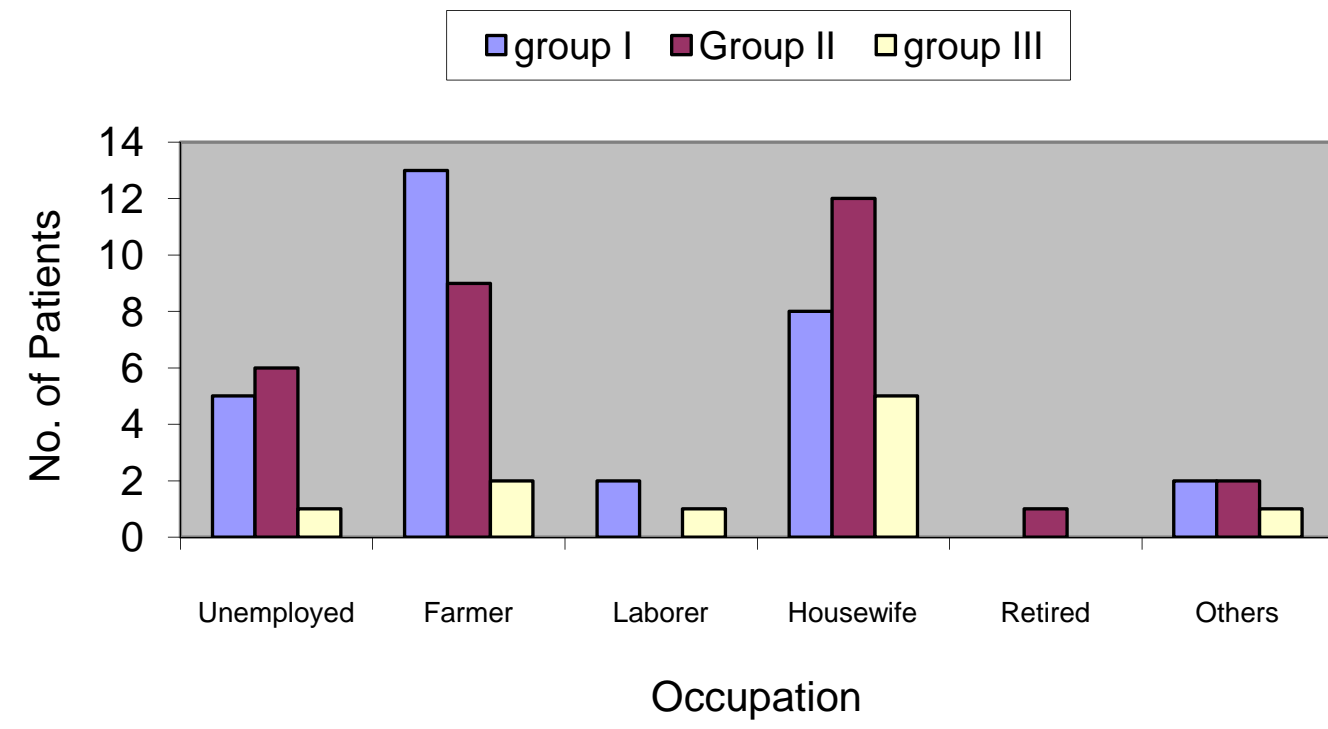

Table 5 Patients Showing EPS

\begin{tabular}{|l|l|l|l|}
\hline \multicolumn{2}{|c|}{} & Group I & Group II \\
\hline No. of Patients & $\mathbf{3 0}$ & $\mathbf{3 0}$ \\
\hline \multirow{4}{*}{ Two Weeks } & EPS & 11 & 5 \\
\cline { 2 - 4 } & Significant EPS & 9 & 4 \\
\cline { 2 - 4 } & \%age EPS & 36.67 & 16.67 \\
\cline { 2 - 4 } & \% Significant EPS & 30 & 13.33 \\
\hline \multirow{5}{*}{ Four Weeks } & EPS & 12 & 6 \\
\cline { 2 - 4 } & Significant EPS & 11 & 4 \\
\cline { 2 - 4 } & \%age EPS & 40 & 20 \\
\cline { 2 - 4 } & \% Significant EPS & 36.67 & 13.33 \\
\hline & EPS & 12 & 6 \\
\cline { 2 - 4 } & Significant EPS & 12 & 20 \\
\cline { 2 - 4 } & \%age EPS & 40 & 13.33 \\
\cline { 2 - 4 } & \% Significant EPS & 40 & \\
\hline
\end{tabular}




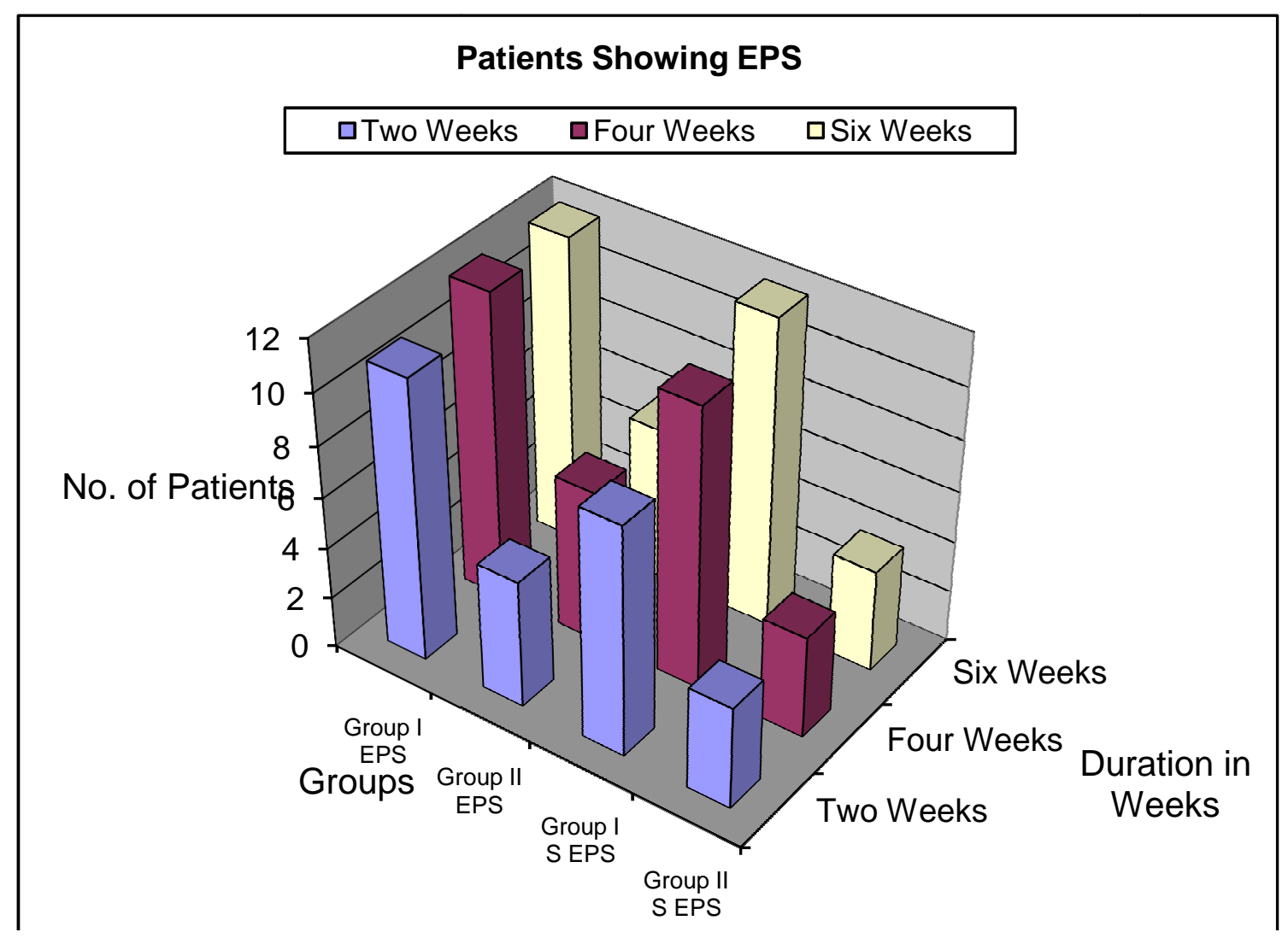

In the above graph EPS is extrapyramidal side effects and S EPS is significant EPS i.e. where SAS score is equal to more than 0.3. In both the groups the S EPS is less than EPS and group II has overall lower incidence of EPS. In group I the S EPS increases with duration of treatment but not the case with group II.

Table 6 Mean SAS Score Of Patients Showing EPS

\begin{tabular}{|c|c|c|c|}
\hline & Two Weeks & Four Weeks & Six Weeks \\
\hline Group I & 0.43 & 0.56 & 0.61 \\
\hline Group II & 0.38 & 0.37 & 0.37 \\
\hline
\end{tabular}

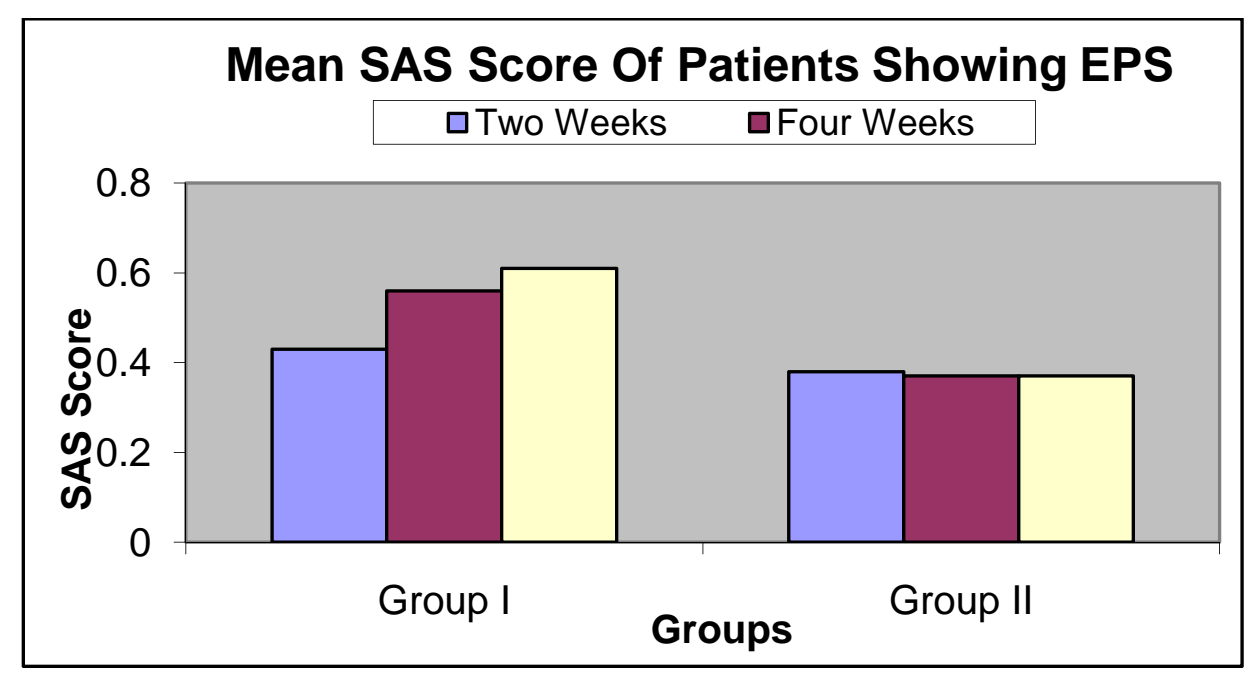


Indo Global Journal of Pharmaceutical Sciences, 2014; 4(2): $91-99$

Table 7 for $p$ value

\begin{tabular}{|l|l|l|l|l|}
\hline Week Vs Week & Basal Vs Two & Two Vs Four & Four Vs Six & Two Vs Six \\
\hline Group I & 0.000 & 0.462 & 0.847 & 0.331 \\
\hline Group II & 0.021 & 0.751 & 1.000 & 0.751 \\
\hline
\end{tabular}

It is evident that the mean SAS score increases with the duration of treatment in case of group I but (almost) not in case of group II.

The test shows highly statistically significant value at basal vs. two weeks in group $I, p=0.000$ and statistically significant value at basal vs. two weeks in case of group II, $\mathrm{p}=0.021$.

Antipsychotics are the most widely prescribed drugs in Psychiatry and mainly used to treat schizophrenia. One of the most important goal in the pharmacological treatment is to provide highly efficacious drugs having fewer side effects, low or no toxicity and high level of tolerability. Almost all of the antipsychotic drugs act by occupying the dopamine receptor and doing so they produce extrapyramidal side effects.

Some studies across the globe have shown that risperidone and olanzapine are better than typical antipsychotic drugs in terms of EPS. No concerned study has been found where risperidone and olanzapine compared in Indian population.

So the present study was carried on 70 patients of schizophrenia diagnosed as per ICD 10. The patients were prescribed with standard dose of risperidone and olanzapine. The primary aim of the study was to compare EPS produced risperidone and olanzapine during different weeks of treatment, and to compare the EPS produced by individual drug at different weeks of treatment. With these purposes in mind, Simpson Angus Scale (SAS) was applied. All the ten parameters of SAS was individually measured and totaled as prescribed in the original article.

In comparing the risperidone and olanzapine the difference at four and six weeks was statistically significant where's in case of basal and two weeks the difference is statistically insignificant. This shows risperidone produces more EPS olanzapine at four and six weeks. In both the groups individually there is a statistically significant difference at basal week and at different weeks of treatment. This shows that both risperidone and olanzapine produces significant EPS. In case of olanzapine group the change in EPS produced along with duration of therapy is statistically insignificant. These results consonance with previous studies [27,28]. In case of risperidone group too the change in EPS produced along with duration of therapy is statistically insignificant. These results are similar with the previous studies done on risperidone [29, 30].

In terms of percentages a number of patients show significant EPS is was much higher in risperidone group then olanzapine group. In comparative study similar results was obtained in study done by Conley and Mahmoud. But the overall percentage of significant EPS is higher than the other global studies. This can be explained by study done by Dhavale Hemangee $\mathrm{S}$ et al [9]. Which shows the patients of Indian origin are prone to suffer EPS when taking antipsychotic drugs.

\section{REFERENCES}

1. Brier A. Cognitive deficit in schizophrenia and its neurochemical basis. Br J Psychatr 1999;174(27):16-8.

2. Simpson JC, Tsuang MT. Mortality among patients with schizophrenia. Schizo Bull 1996;22:485-99.

3. Kane JM. Schizophrenia. N Engl J Med. 1996;334:34.

4. Sadock BJ, Sadock VA. Kaplan and Sadocks Synopsis of Psychiatry, 9th ed. Philadelphia: Williams \& Wilkins; 2003. p.471-504.

5. Dhavale HS, Pinto C, Dass J, et al. Prophylaxis of Antipsychotic- induced Extrapyramidal Side Effects in East Indians: Culture Practice or Biological Necessity? J Psychatr Pract 2004;0(3):200-2.

6. Stahl SM: Essential Psychopharmacology. New York, Cambridge University Press, 1996. p.263-88.

7. Delay J, Denikar P. Le traitement des psychoses par une methode neurolytique derive de 1 liberotherapie. Compets Rendus du Congr Alien Neurol 1952;50:503-13.

8. Jan Volavka, Pal Czobor, Brian Sheitman, et al. Clozapine, Olanzapine, Risperidone, and Haloperidol in the Treatment of Patients With Chronic Schizophrenia and Schizoaffective Disorder . Focus 2004;2:59-67.

9. Hamann J, Langer B, Leucht S, et al. Medical Decision Making in Antipsychotic Drug Choice for Schizophrenia. Am J Psychiatr 2004;161:1301-4.

10. Keneday Y, Kawamura I, Fujii A, et al. Impact of a switch for typical to atypical antipsychotic drugs on quality of life and gonadal hormones in male patients with schizophrenia. Neuro Endocrinol Lett. 2004;25(1-2):13540.

11. Van Patten T. Why do schizophrenic patients refuse to take their drugs?. Arch Gen Psychiatr 1974;31:67-72.

12. Mark G. Risk of extrapyramidal syndromes with haloperidol, risperidone, and olanzapin. Annals of Pharmacother 2001;35:1517-22.

13. Kane J, Honigfeld G, Singer $J$, et al. Clozapine for treatment resistant schizophrenic. A double-blind placebo comparision with chlorpromazine. Arch Gen Psychiatr 1988;45:789-96.

14. Small JG, Hirsch SR, Arvanitis LA, et al. Quetiapine in patients with schizophrenia. A high- and low-dose double- 


\section{Indo Global Journal of Pharmaceutical Sciences, 2014; 4(2): $91-99$}

blind comparision with placebo. Seroquel Study Group. Arch Gen Psychiatr 1997;54:549-57.

15. Dev V, Raniwalla J. Quetiapine: A review of its safety in the management of schizophrenia. Drug Safety 2000;23:295-307.

16. Chouinard G. Effects of risperidone in tradive dyskinesia: An analysis of the Canadian multicentre risperidone study. J Clin Psychopharmacol 1995;15:36S-44S.

17. Tollefson GD, Beasley CMJ, Tamura RN et al. Blind, controlled, longterm study of comperative incidence of treatment-emergent tardive dyskinesia with olanzapine or haloperidol. Am J Psychiatr 1997; 154:1248-54.

18. Olanow CW, Tatton WG. Etiology and pathogenesis of parkinson's disease. Annu Rev Neurosc 22:123-144.

19. Magnuson TM, Keller BK, Burke WJ. Extrapyramidal Side Effects in a Patient Treated With Risperidone Plus Donepezil. Am J Psychiatr 1998;155:1458-9.

20. Owens DG: Extrapyramidal side effects and tolerability of risperidone: a review. J Clin Psychiatr 1994;55(5 suppl):29-35.

21. Casey DE. Tardive dyskinesia and atypical antipsychotic drugs. Schizophr Res 1999;35 Suppl:S61-S66.

22. Casey DE. Neuroleptic-induced acute extrapyramidal syndromes and tardive dyskinesia. Psychiatr Clin North Am 1993;16:589- 609.
23. Tarsy D, Baldessarini RJ, Tarazi FI. Effects of newer antipsychotics on extrapyramidal functions. CND Drugs. 2002;16(1):23-45.

24. Kane JM. Newer antipsychotic drugs. A review of their pharmacology and therapeutic potential. Drugs 1993;46:585-93.

25. Kane JM. Extrapyramidal side effects are unacceptable Eur Neuropsychopharmacol 2001;11 Suppl 4:S397-403.

26. Simpson GN, Angus JWS. A rating scale for extrapyramidal side effects. Acta Psychiatr Scand. 1970;212 Suppl 44:11-19.

27. Simpson GN, Angus JWS. A rating scale for extrapyramidal side effects. Acta Psychiatr Scand. 1970;212 Suppl 44:11-19.

28. Liberman JA, Tollefson G, Tohen $\mathrm{M}$ et al. Comperative efficacy and safety of atypical and conventional antipsychotic drugs in first episode of psychosis: A randomized, double blind trial of olanzapine versus haloperidol. Am J Psychatr 2003;160:1396-1404.

29. Biswasl PN, Wilton LV, Pearcel GL, et al. The pharmacovigilance of olanzapine: results of a postmarketing surveillance study on 8858 patients in England. J Psychopharmacol 2001;15(4):265-71.

30. Wirshing WC. Movement disorders associated with neuroleptic treatment. J Clin Psychiat 2001;62:15-8.

ID: 101610675) indexed and abstracted in EMBASE(Elsevier), SCIRUS(Elsevier),CABI, CAB Abstracts, Chemical Abstract Services(CAS), American Chemical Society(ACS), Index Copernicus, EBSCO, DOAJ, Google Scholar and many more. For further details, visit 